Revista PSICOLOGIA, 2020, Vol. 34 (2), 215-224. doi: 10.17575/psicologia.v34i2.1652

\title{
Psicologia vocacional no ensino da psicologia em Portugal
}

\author{
Inês Castro ${ }^{1}$, Joana Soares ${ }^{1}$, Ana Daniela Silva ${ }^{2}$ \& Cátia Marques ${ }^{3}$ \\ ${ }^{1}$ Associação Portuguesa para o Desenvolvimento da Carreira \\ ${ }^{2}$ Escola de Psicologia, Universidade do Minho \\ 3 Instituto Politécnico do Porto
}

\begin{abstract}
Resumo: 0 presente estudo procura perceber a representatividade da Psicologia Vocacional nos cursos de Psicologia lecionados no ano letivo 2019/20 em Portugal. Recorreu-se a análises de frequência e de conteúdo das unidades curriculares de cada curso, de forma a distribuí-las pelas especialidades gerais e avançada de Psicologia Vocacional e Desenvolvimento da Carreira, definidas pela Ordem dos Psicólogos Portugueses. Entre 173 instituições de ensino superior português, 31 ministram cursos de Psicologia, perfazendo um total de 109 cursos. Destes, 26 são licenciaturas, 55 mestrados, cinco mestrados integrados e 23 doutoramentos. Das 1.167 unidades curriculares analisadas, entre os 46 cursos selecionados, constatou-se que aproximadamente $2.7 \%$ abordam temáticas da Psicologia Vocacional e do Desenvolvimento de Carreira. Isto demonstra a necessidade de afirmar esta área no ensino da Psicologia, de forma a promover competências-chave essenciais à gestão pessoal de carreira. Assim, os/as psicólogos/as estarão capazes de enfrentar múltiplos desafios de carreira e intervir junto da comunidade.
\end{abstract}

Palavras-chave: Psicologia vocacional; desenvolvimento da carreira; ensino superior; especialidades profissionais.

Vocational psychology in psychology education in Portugal: This study aims to understand the representativeness of Vocational Psychology across Psychology courses taught in 2019/20 academic year, in Portugal. Frequency and content analysis of each courses' curricular units were run, to distribute these units by general Psychology specialties and advanced Vocational Psychology specialty, defined by Portuguese Psychologists Association. Among 173 Portuguese higher education institutions, 31 teach Psychology courses, making a total of 109 courses. Of these, 26 are undergraduate, 55 masters, five integrated masters and 23 doctorates degrees. In regard to the 1167 curricular units analyzed, from de 46 courses selected, approximately $2.7 \%$ address themes of Vocational and Career Development Psychology. This demonstrate the need to affirm this area of knowledge in Psychology training, to promote useful key competencies for personal career management. Therefore, psychologist will be able to face multiple career challenges and intervene among the community.

Keywords: Vocational psychology; career development; higher education; professional specialties.

A Ordem dos Psicólogos Portugueses (OPP) confere o título de psicólogo/a especialista, a todo o profissional certificado com competências demonstradas na área de respetiva especialidade (Regulamento n. - 107-A/2016). Foram reconhecidos pela OPP dois níveis de especialidade: gerais (Psicologia Clínica e da Saúde, Psicologia da Educação e Psicologia do Trabalho, Social e das Organizações) e avançadas (e.g., Psicologia da Justiça, Psicologia Vocacional e do Desenvolvimento da Carreira, Psicologia Comunitária). Estas definem-se por um corpo teórico independente, com ampla investigação e atividade profissional (e.g., diagnóstico, intervenção, avaliação). Desta forma, atribui-se o título de especialista a todo o/a psicólogo/a que atue e adquira formação contínua nas respetivas especialidades, cumprindo os critérios éticos associados à profissão (Regulamento n.o 107-A/2016). Atualmente, a especialidade avançada em Psicologia Vocacional e do Desenvolvimento da Carreira parece estar a receber um maior destaque por parte da comunidade científica, técnica e civil devido, em parte, às rápidas alterações ao nível da inteligência artificial, automatização e globalização (Blustein et al., 2019; Cedefop, 2019; Whiston \& Blustein, 2013). Estas rápidas e constantes alterações, que marcam o mercado de emprego do século XXI, geram maior competitividade, instabilidade e exigem mais e novas competências aos indivíduos, nomeadamente, maior capacidade de adaptação e renovação de conhecimentos (e.g., Comissão Europeia, 2019; Duarte et al., 2010; Fórum Económico Mundial, 2018; Savickas, 2012). A construção de carreira na

1 Morada para correspondência: Ana Daniela Silva, Edifício da escola de psicologia - Universidade do Minho, Campus de Gualtar, 4710-056 Braga, Portugal. E-mail: danielasilva@psi.uminho.pt 
contemporaneidade torna-se assim mais exigente, podendo despoletar sentimentos de ansiedade e insegurança nos indivíduos (Savickas, 2012).

Os/as psicólogos/as de carreira podem auxiliar os indivíduos a ultrapassar estes sentimentos, munindo-os de recursos que lhes permitam enfrentar os inúmeros desafios que o mundo laboral coloca, como as múltiplas e (in)esperadas transições de carreira, necessidade de ambientes laborais inclusivos, atualização de competências técnicas e desenvolvimento ou aprimoramento de competências pessoais (e.g., autonomia, pensamento crítico, resolução de problemas) (e.g., Blustein et al., 2019; Gama et al., 2018; Lent, 2018; Savickas, 2012). As intervenções de carreira contribuem, assim, para o aprimoramento do potencial e saúde mental do individuo, tornando as sociedades mais justas e a economia mais eficiente (Blustein et al., 2019; Cedefop, 2019). Porém, para que estas intervenções sejam eficazes e respondam às necessidades dos indivíduos, há 11 competências-chave que são apontadas como indispensáveis no perfil de competências dos/as psicólogos/as de carreira: (1) conhecimento sobre teorias de desenvolvimento de carreira; (2) aconselhamento individual e em grupo; (3) avaliação individual e em grupo; (4) recursos e conhecimento sobre a prática de aconselhamento de carreira; (5) desenvolver, planear, gerir e implementar programas de carreira em diferentes contextos e (6) populações; (7) conhecimento e competências sobre coaching, consultoria e otimização do desempenho; (8) conhecimentos e competências de supervisão; (9) ética profissional; (10) conhecimentos e competências de prática investigativa no âmbito de carreira; e (11) conhecimento sobre a utilização de tecnologias em contexto prático (IAEVG, 2018; NCDA, 2009). Além destas competências-chave, é igualmente importante que estes profissionais saibam adotar uma linguagem clara e adequada aos/às clientes e colegas, bem como estar conscientes das suas capacidades e limitações (IAEVG, 2018). Segundo Cordeiro e colaboradores (2018), no ano letivo 2015/16, as ofertas formativas das instituições de ensino superior português, no âmbito da Psicologia Vocacional e do Desenvolvimento da Carreira, centraram-se essencialmente no desenvolvimento de conhecimentos teóricos, avaliação e intervenção de carreira. Dos resultados apresentados pelos autores (Cordeiro et al., 2018), identifica-se alguma carência formativa ao nível de competências-chave como a ética profissional, a utilização de tecnologia em contexto prático, os conhecimentos e competências de supervisão, planeamento e execução de intervenções de carreira ajustadas a diferentes contextos e populações.

\section{Sistema de Ensino Superior}

Com o intuito de compreender o panorama da formação em Psicologia Vocacional e do Desenvolvimento da Carreira em Portugal, é necessário conhecer as mudanças do sistema de ensino superior português, assim como a evolução da oferta formativa em Psicologia. Em 1999, Portugal e mais 28 estados membros da União Europeia, posteriormente alargados para 48 (Comissão Europeia, 2018), assinaram a Declaração de Bolonha que visa melhorar a empregabilidade e mobilidade dos cidadãos, bem como, tornar o ensino superior europeu mais competitivo (Decreto-Lei n.o 107/2008). Para cumprir estes objetivos, as instituições de ensino superior foram progressivamente restruturando os cursos e unificando o sistema de avaliação. Resultaram, assim, três ciclos de estudo e um sistema de avaliação, conhecido como o European Credit Transfer and Accumulation System (ECTS). 0 primeiro ciclo (licenciatura) tem a duração de três anos e uma carga horária mínima de 180 ECTS (Decreto-Lei n. ${ }^{\circ}$ 107/2008). 0 segundo ciclo (mestrado) tem a duração de dois anos e uma carga horária mínima entre 90 a 120 ECTS (Decreto-Lei n.o 107/2008). Quando o segundo ciclo se junta ao primeiro, passa a perfazer um total de cinco anos (mestrado integrado) com uma carga horária mínima entre 300 a 360 ECTS (Decreto-Lei n. $\stackrel{0}{107 / 2008) . ~} 0$ terceiro ciclo (doutoramento) tem a duração de três anos (Decreto-Lei n.o 107/2008). Com a adoção da Declaração de Bolonha, os países procuraram atender às exigências da sociedade (e.g., globalização, competitividade dos mercados), ao mesmo tempo que resolviam a crise identitária das instituições de ensino superior europeias (Macedo, 2017). Apesar dos resultados positivos alcançados, esta reforma parece ter sido feita apenas de forma parcial (Macedo, 2017), uma vez que ainda se verifica um distanciamento económico, pedagógico e metodológico entre as diferentes esferas educativas (ensino básico, secundário e superior), bem como entre as instituições de ensino superior e as necessidades do mercado de emprego (Macedo, 2017). Para além disso, esta reestruturação parece não ter sido acompanhada da definição de um perfil claro de competências, nomeadamente para os/as psicólogos/as que intervêm em contexto escolar (Mendes et al., 2015).

Em Portugal, a reforma do sistema de ensino superior levou a um aumento do número de licenciaturas, de quatro em 1990 para 10 em 1995, tendo atingido o pico em 2007 com um total de 37 licenciaturas (Coelho et al., 2012). Posteriormente, observou-se o padrão inverso, verificando-se um decréscimo para 32 licenciaturas no ano letivo de 2011/2012. Apesar disso, Portugal foi destacado como o país com um maior número de cursos em Psicologia por milhão de habitantes (Coelho et al., 2012). No ano letivo de 2015/16, este decréscimo continuou passando para 26 (29.2\%) licenciaturas entre os 89 cursos 
de psicologia (Cordeiro et al., 2018). A par desta reforma educativa, é importante notar outra questão contextual. Ainda que, o número de desempregados diplomados tenha sofrido uma quebra de $56006 \mathrm{em}$ dezembro de 2017 para 45767 em dezembro de 2018, este permanece elevado (Direção-Geral de Estatísticas de Educação e Ciência do Ministério da Educação e Ciência, 2018). Segundo os dados disponibilizados pela Direção-Geral de Estatísticas de Educação e Ciência do Ministério da Educação e Ciência (DGEEC, 2015, 2016, 2017, 2018), a Psicologia continua a ser a área com mais diplomados nesta condição, apresentando em 2018 um valor de 4787 (11.9\%) indivíduos desempregados, logo após a área de ciências empresariais e administração ( $n=7611,19 \%)$. Reforça, assim, a urgência na análise e reflexão sobre a oferta formativa em Psicologia, especificamente em Psicologia Vocacional e do Desenvolvimento de Carreira. Esta permite a formação de profissionais especializados e faculta competências de gestão pessoal de carreira úteis a todos/as os/as psicólogos/as que se encontrem em situação de transição de carreira, como é o caso do desemprego. Ainda que a OPP disponha de um conjunto de propostas para a integração e criação de emprego aos/às psicólogos/as no Sistema Nacional de Saúde, Agrupamentos de Escolas Públicas e serviços prisionais (e.g., OPP, 2013, 2016, 2018), esta análise é primordial para a otimização das medidas pré-existentes e desenvolvimento de outras. Desta forma, será possível auxiliar estes profissionais e responder prontamente às exigências da sociedade.

Como tal, o presente estudo procurou analisar as unidades curriculares dos cursos de Psicologia lecionados em Portugal e em funcionamento no ano letivo 2019/2020, recorrendo a metodologias quantitativas e qualitativas. 0 objetivo é compreender como a Psicologia Vocacional está presente nos diferentes ciclos de estudo comparativamente às restantes especializações gerais definidas pela OPP (Regulamento n.. 107-A/2016).

\section{MÉTODO}

\section{Amostra}

A amostra do presente estudo é constituída por 109 cursos de Psicologia, ministrados em 31 instituições do ensino superior em Portugal. Nesta amostra foram incluídas todas as instituições, do ensino privado ( $n$ $=19,61.3 \%)$ e do público $(n=12,38.7 \%)$, que incluem o curso de Psicologia na sua oferta formativa. No que respeita ao ciclo de estudos, estes cursos estão distribuídos por 26 licenciaturas, 55 mestrados, cinco mestrados integrados e 23 doutoramentos, discriminados na Tabela 1.

Na segunda fase deste estudo, a qual correspondeu à análise dos planos curriculares em função das especialidades definidas pela OPP (Regulamento n.- 107-A/2016), foram excluídas as instituições que não disponibilizam, em formato online, os conteúdos programáticos das suas unidades curriculares. Assim, foram analisados 46 cursos de Psicologia, de 17 instituições de ensino superior, distribuídos por 13 licenciaturas, 29 mestrados e quatro mestrados integrados.

\section{Procedimento e Análises}

Os procedimentos adotados para a fase inicial deste estudo seguiram as diretrizes de Cordeiro e colaboradores (2018). Assim, o primeiro momento da investigação consistiu na identificação das instituições do ensino superior, públicas e privadas, que ministram o curso de Psicologia em Portugal, no portal da Direção-Geral do Ensino Superior (DGES, 2019). Neste portal, acedeu-se ao separador "instituição/curso", sendo que para cada tipo de instituição de ensino superior recolheu-se os cursos na área de Psicologia. Posto isto, foram consultados os respetivos websites das instituições de ensino superior para se aceder à totalidade dos planos curriculares dos três ciclos de estudos superiores. A recolha de dados foi realizada no mês de dezembro de 2019, sendo descritiva dos cursos disponibilizados no ano letivo de 2019/2020. 0 objetivo desta fase consistiu na descrição do panorama do ensino da Psicologia em Portugal. Em termos da contabilização dos ciclos de estudo, cada mestrado integrado não foi separado nas suas especializações.

Num segundo momento, após a exclusão das instituições que não disponibilizam os conteúdos programático em formato online, procurou-se distribuir as unidades curriculares pelas três especialidades gerais e a especialidade avançada de Psicologia da Educação (Intervenção Precoce, Necessidades Educativas Especiais e Psicologia Vocacional e Desenvolvimento de Carreira). Para tal, recorreu-se aos critérios estabelecidos no regulamento n.o 107-A/2016 da OPP. Posteriormente, foram definidas e identificadas palavras-chave (e.g., "carreira" e "vocacional") no nome das unidades curriculares e nos conteúdos programáticos das mesmas. Foram, assim, efetuadas análises quantitativas de frequência absoluta e relativa às unidades curriculares. Para uma compreensão mais adequada dessa distribuição, foram também estabelecidas duas categorias designadas por "gerais" e "outras áreas". A primeira categoria inclui as unidades curriculares consideradas de base para a formação em Psicologia (e.g., Epistemologia e História da Psicologia). A segunda categoria inclui as unidades curriculares no âmbito de outras áreas 
científicas (e.g., Neurociências e Antropologia). Na distribuição pelas especialidades avançadas foram identificadas unidades curriculares que abrangiam mais do que uma especialidade, assim, sempre que necessário, foram elaboradas categorias combinatórias (e.g., Intervenção Precoce e Necessidades Educativas Especiais). As unidades curriculares comuns a diferentes ciclos de ensino, numa mesma instituição, foram consideradas como duplicadas e, como tal, foram excluídas da análise. Adicionalmente, não se estendeu as análises ao ciclo de doutoramento, pois uma parte substancial das unidades curriculares disponíveis focam-se em métodos de investigação, não sendo percetível a presença das temáticas em estudo. Num terceiro momento, realizou-se uma análise temática aos conteúdos programáticos das unidades curriculares referentes à especialidade avançada de Psicologia Vocacional e do Desenvolvimento da Carreira. Para tal, foram adotados os critérios de inclusão e as categorias de Cordeiro e colaboradores (2018). As análises foram efetuadas por duas investigadoras com recurso ao Microsoft Office Excel, versão 2013, para Windows, e avaliadas por uma investigadora independente qualificada.

Tabela 1. Lista das instituições de ensino por ciclos de estudo

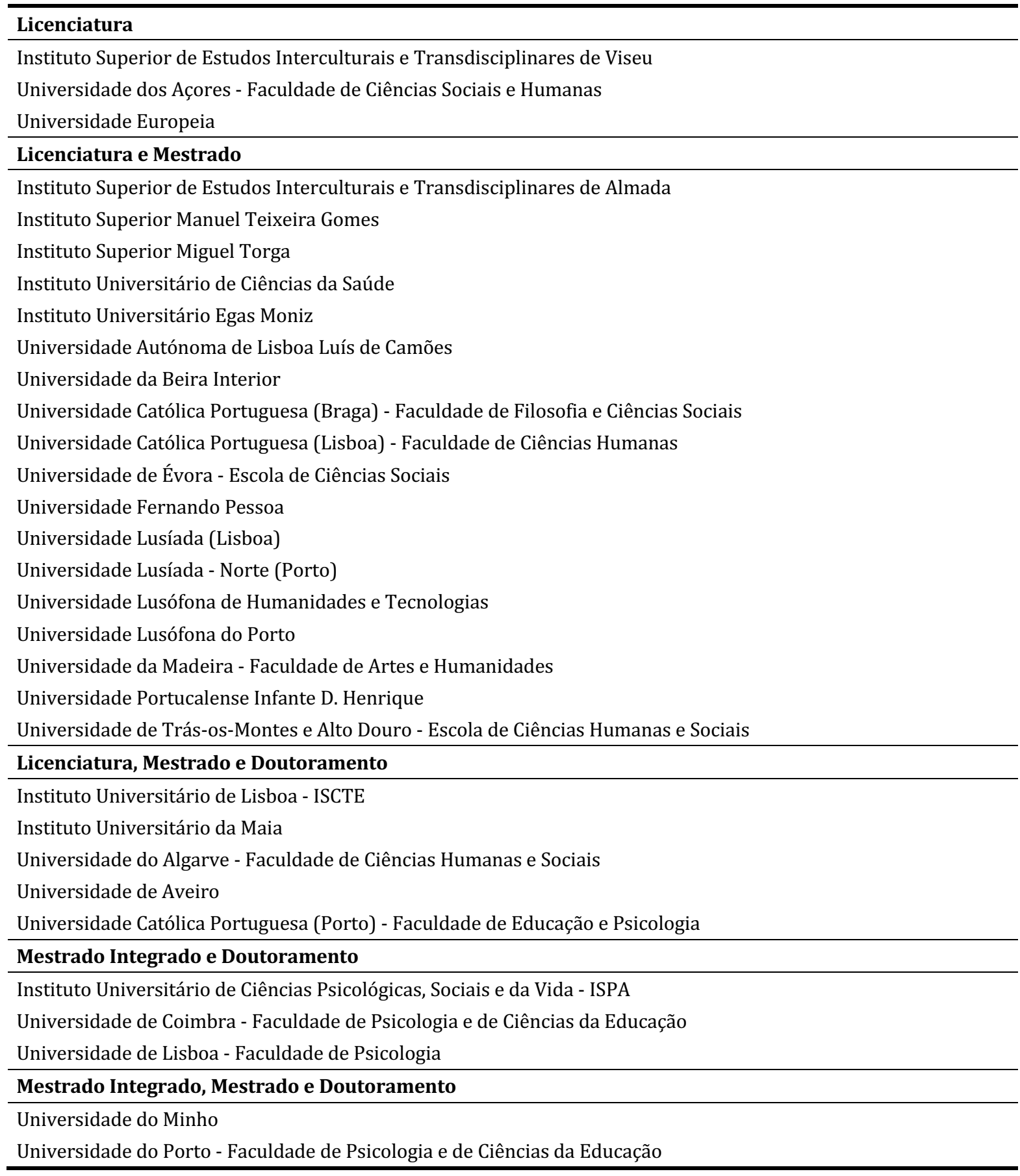




\section{RESULTADOS}

Os 109 cursos de Psicologia analisados no presente estudo estão distribuídos pelos três ciclos de estudos superiores de 31 instituições públicas e privadas. Em termos da licenciatura, constataram-se uma totalidade de 26 cursos (23.9\%), dos quais oito são ministrados em instituições do ensino superior público e 18 do ensino superior privado. No segundo ciclo de estudos, identificaram-se 55 (50.5\%) mestrados de diferentes áreas de especialização, sendo 16 do ensino público e 39 do privado. Por sua vez, os cinco mestrados integrados contabilizados (4.6\%) encontram-se distribuídos por cinco instituições de ensino público universitário e uma de ensino privado. No terceiro ciclo de estudos foram identificados 14 doutoramentos lecionados no ensino público e nove no privado, perfazendo um total de 23 doutoramentos (21.1\%) no âmbito da Psicologia em Portugal (ver Figura 1).

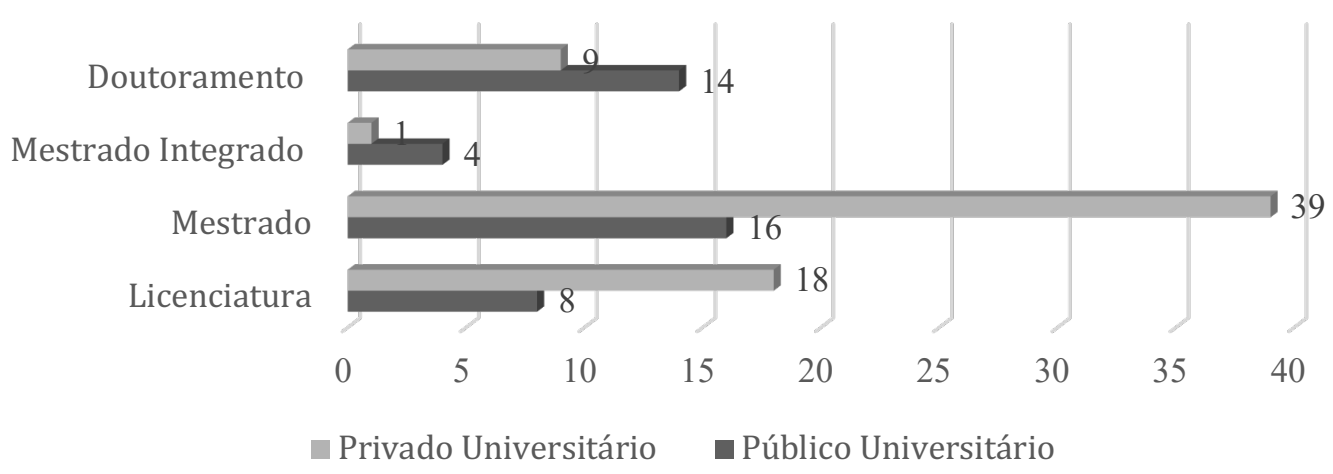

Figura 1. Distribuição dos ciclos de cursos no âmbito da psicologia.

\section{Especialidades da Ordem}

Para a exploração da distribuição das unidades curriculares pelas especialidades da OPP, foram analisados 46 cursos de Psicologia, de oito instituições de ensino privado universitário e nove de ensino público. Desta forma, foram estudados os conteúdos programáticos de 1166 unidades curriculares, ministradas em 13 licenciaturas (28.3\%), 29 mestrados (63.0\%) e quatro mestrados integrados (8.7\%). Constatou-se que a especialidade geral de Psicologia Clínica apresenta um valor substancialmente superior de unidades curriculares ( $n=319,27.4 \%)$, seguida pela Psicologia do Trabalho, Social e das Organizações $(n=135$, $11.6 \%)$ e, por último, pela Psicologia da Educação $(n=92,7.9 \%)$. No que se refere aos ciclos de estudos, a maior discrepância entre especialidades gerais ocorre nos mestrados, nos quais foram identificadas 166 unidades curriculares de Psicologia Clínica, 51 de Psicologia do Trabalho, Social e das Organizações e 27 da Psicologia da Educação. Os restantes valores das distribuições das unidades curriculares pelos ciclos de estudos e especialidades gerais estão discriminados na Tabela 2.

Tabela 2. Frequência Absoluta da Distribuição das UC’s pelas Especialidades da OPP

\begin{tabular}{lcccc}
\hline & Licenciatura & Mestrado & Mestrado Integrado & Total \\
\hline Geral & 304 & 94 & 142 & 540 \\
P.C. & 47 & 166 & 106 & 319 \\
P. T. S. O. & 34 & 51 & 50 & 135 \\
P. E. & 22 & 27 & 43 & 92 \\
$\quad$ IP & & 2 & 2 & 4 \\
NEE & 3 & 7 & 13 & 23 \\
PVDC & 8 & 6 & 13 & 27 \\
Geral & 8 & 9 & 12 & 29 \\
IP e NEE & 1 & 1 & 2 & 4 \\
NEE e PVDC & 2 & 2 & 1 & 5 \\
Outras áreas & 47 & 9 & 24 & 80 \\
\hline
\end{tabular}

Nota. P.C. = Psicologia Clínica, P.T.S.O. = Psicologia do Trabalho, Social e das Organizações, P.E. = Psicologia da Educação; IP = Intervenção Precoce, NEE = Necessidades Educativas Especiais, $\mathrm{PVDC}=$ Psicologia Vocacional e do Desenvolvimento da Carreira 
No que respeita às unidades curriculares que integram a especialidade de Psicologia da Educação, foram categorizadas 27 no âmbito da Psicologia Vocacional e Desenvolvimento da Carreira (29.4\%), 23 em Necessidades Educativas Especiais (25\%) e quatro na área da Intervenção Precoce (4.4\%). Constatou-se, também, a existência de unidades curriculares que combinaram temáticas das Necessidades Educativas Especiais com a Intervenção Precoce $(n=4,4.4 \%)$ e com conteúdos da Psicologia Vocacional e Desenvolvimento da Carreira $(n=5,5.4 \%)$. Analisando a totalidade de unidades curriculares $(n=1166)$ a Psicologia Vocacional e Desenvolvimento de Carreira tem uma representatividade aproximada de $2.7 \%$. A distribuição das restantes unidades curriculares pode ser observada na Tabela 2.

\section{Unidades Curriculares}

No âmbito da Psicologia Vocacional e do Desenvolvimento da Carreira foram contabilizadas 32 unidades curriculares, distribuídas por sete licenciaturas, seis mestrados e quatro mestrados integrados. Destas, 15 abordam também outras áreas da Psicologia, enquanto 17 se focam exclusivamente em conteúdos da psicologia vocacional. Estas unidades curriculares foram distribuídas pelas cinco categorias de Cordeiro e colaborados (2018), sintetizadas na Tabela 3. Com exceção de três unidades curriculares, designadas por Psicologia da Educação; Psicologia da Educação e da Orientação; Seminário Temático I: gestão de carreira, criatividade e inovação, empreendedorismo. Já que os conteúdos programáticos disponibilizados não permitem a inclusão exclusiva em uma única categoria.

Tabela 3. Distribuição das unidades curriculares no âmbito da Psicologia Vocacional e do Desenvolvimento de Carreira pelas categorias de Cordeiro e colaboradores (2018)

\begin{tabular}{|c|c|}
\hline $\begin{array}{c}\text { Unidades } \\
\text { Curriculares }\end{array}$ & Conteúdos \\
\hline \multicolumn{2}{|c|}{ Concetualização teórica, avaliação e intervenção em problemáticas da Psicologia da Carreira } \\
\hline $\begin{array}{l}\text { Aconselhamento em } \\
\text { Contextos } \\
\text { Educativos }\end{array}$ & $\begin{array}{l}\text { Perspetivas teóricas, etapas e técnicas de avaliação psicológica em Psicologia } \\
\text { Vocacional e do Desenvolvimento da Carreira; } \\
\text { Aconselhamento vocacional em momentos de transição normativa e para populações } \\
\text { com problemáticas específicas. }\end{array}$ \\
\hline $\begin{array}{l}\text { Consulta Psicológica } \\
\text { de Orientação } \\
\text { Vocacional }\end{array}$ & $\begin{array}{l}\text { Perspetivas teóricas da Psicologia Vocacional; } \\
\text { Dimensões estruturantes da intervenção; } \\
\text { Atividades de formação nas tarefas de elaboração, implementação e avaliação da } \\
\text { consulta psicológica de orientação vocacional. }\end{array}$ \\
\hline $\begin{array}{l}\text { Consulta Psicológica } \\
\text { Vocacional e } \\
\text { Aconselhamento de } \\
\text { Carreira }\end{array}$ & $\begin{array}{l}\text { Quadros, contextos, finalidades e eficácia da intervenção vocacional; } \\
\text { Consulta psicológica vocacional: modelos, fases e avaliação psicológica. }\end{array}$ \\
\hline $\begin{array}{l}\text { Desenvolvimento } \\
\text { Pessoal e Vocacional }\end{array}$ & $\begin{array}{l}\text { O desenvolvimento vocacional no quadro do desenvolvimento pessoal; } \\
\text { Modelos e perspetivas teóricas sobre o desenvolvimento vocacional; } \\
\text { Intervenção psicológica no domínio vocacional: contextos, processos e estratégias. }\end{array}$ \\
\hline $\begin{array}{l}\text { Gestão do Projeto de } \\
\text { Vida na Adultez } \\
\text { Tardia }\end{array}$ & $\begin{array}{l}\text { Constructos e modelos teóricos do desenvolvimento psicológico e orientação } \\
\text { vocacional ao longo do ciclo de vida; } \\
\text { Estratégias de apoio e aspetos éticos inerentes à gestão do projeto de vida na adultez } \\
\text { tardia; } \\
\text { Elaboração, implementação e avaliação de modalidades de apoio vocacional dirigidas a } \\
\text { públicos seniores. }\end{array}$ \\
\hline $\begin{array}{l}\text { Orientação } \\
\text { Vocacional }\end{array}$ & Principais modelos e constructos da Psicologia Vocacional. \\
\hline $\begin{array}{l}\text { Psicologia Vocacional } \\
\text { a) }\end{array}$ & $\begin{array}{l}\text { Definição epistemológica, resenha histórica e contextualização da Psicologia } \\
\text { Vocacional; } \\
\text { Teorias Psicológicas do Comportamento Vocacional e constructos associados ao } \\
\text { trabalho, formação profissional e carreiras; } \\
\text { Contextos e intervenção de Consulta Vocacional. }\end{array}$ \\
\hline $\begin{array}{l}\text { Psicologia Vocacional } \\
\text { a) }\end{array}$ & $\begin{array}{l}\text { Atitudes, estratégias e resultados de carreira, associados ao papel de trabalhador; } \\
\text { Transição escola-trabalho; } \\
\text { Teorias da Carreira (e.g., sociocognitiva, objetivos de realização, autodeterminação); } \\
\text { Intervenção vocacional na implementação de programas de treino de atitudes, } \\
\text { estratégias e adaptabilidade de carreira. }\end{array}$ \\
\hline $\begin{array}{l}\text { Temas de } \\
\text { Desenvolvimento de } \\
\text { Carreira do Adulto }\end{array}$ & $\begin{array}{l}\text { Teorias e modelos sistémicos, desenvolvimentistas e construtivistas da carreira; } \\
\text { Fatores de género, raça, classe e relações sociais no desenvolvimento de carreira; } \\
\text { Modelos para desenvolvimento da Carreira: gestão e criatividade. }\end{array}$ \\
\hline
\end{tabular}




\begin{tabular}{|c|c|}
\hline $\begin{array}{l}\text { Unidades } \\
\text { Curriculares }\end{array}$ & Conteúdos \\
\hline \multicolumn{2}{|r|}{ Desenvolvimento de Competências de Carreira dos/as Estudantes } \\
\hline $\begin{array}{l}\text { Aprendizagem e } \\
\text { Gestão de } \\
\text { Competências } \\
\text { Académicas }\end{array}$ & $\begin{array}{l}\text { Planeamento pessoal centrado na reflexividade e no autoconhecimento, através de } \\
\text { projetos de vida que sistematizem o autoconhecimento, identificação e mobilização de } \\
\text { recursos pessoais e do contexto, processos de tomada de decisão e de transição. }\end{array}$ \\
\hline $\begin{array}{l}\text { Desenvolvimento de } \\
\text { Competências } \\
\text { Profissionais }\end{array}$ & $\begin{array}{l}\text { Estabelecer um plano a curto/médio prazo de trajetória profissional (e.g., processo, } \\
\text { método instrumentos de procura de emprego, recursos pessoais, entrevista). }\end{array}$ \\
\hline $\begin{array}{l}\text { Exploração } \\
\text { Vocacional I (Job } \\
\text { Shadowing) } \\
\text { Exploração } \\
\text { Vocacional II (Job } \\
\text { Shadowing) }\end{array}$ & $\begin{array}{l}\text { Imersão e contacto tutorial em contexto profissional; } \\
\text { Observação de diferentes realidades profissionais e institucionais; } \\
\text { Proporciona o desenvolvimento de objetivos de carreira. }\end{array}$ \\
\hline $\begin{array}{l}\text { Projeto de } \\
\text { Desenvolvimento } \\
\text { Pessoal e Profissional }\end{array}$ & $\begin{array}{l}\text { Construção de um projeto idiossincrático de desenvolvimento pessoal e profissional, } \\
\text { que integre as experiências vividas ao longo da vida académica, partindo da reflexão } \\
\text { sobre o seu próprio desenvolvimento e da antecipação das metas e objetivos a } \\
\text { alcançar. }\end{array}$ \\
\hline $\begin{array}{l}\text { Seminário de } \\
\text { Desenvolvimento de } \\
\text { Competências } \\
\text { Académicas e } \\
\text { Profissionais }\end{array}$ & $\begin{array}{l}\text { Desenvolver conhecimentos sobre o processo de gestão pessoal de carreira } \\
\text { (autoconhecimento, conhecimento do mundo, tomada de decisão e implementação da } \\
\text { decisão). }\end{array}$ \\
\hline \multicolumn{2}{|c|}{ Desenvolvimento de conhecimentos e competências inerentes à avaliação psicológica da carreira } \\
\hline $\begin{array}{l}\text { Avaliação em } \\
\text { Contextos de } \\
\text { Aconselhamento } \\
\text { Vocacional }\end{array}$ & $\begin{array}{l}\text { Conhecimentos básicos de psicometria e de métodos de avaliação psicológica no } \\
\text { âmbito da intervenção e aconselhamento de carreira. }\end{array}$ \\
\hline $\begin{array}{l}\text { Avaliação e } \\
\text { Intervenção } \\
\text { Psicoeducacional Ib) }\end{array}$ & Modelos e teorias do processo de desenvolvimento vocacional e suas aplicações. \\
\hline $\begin{array}{l}\text { Avaliação } \\
\text { Psicológica em } \\
\text { Contexto da Carreira }\end{array}$ & $\begin{array}{l}\text { Avaliação psicológica e aconselhamento; } \\
\text { Modelos teóricos do autoconceito vocacional, processos desenvolvimentais e } \\
\text { motivacionais. }\end{array}$ \\
\hline $\begin{array}{l}\text { Avaliação } \\
\text { Psicológica em } \\
\text { Psicologia da } \\
\text { Educação }\end{array}$ & $\begin{array}{l}\text { Conhecimento, manipulação, cotação e interpretação de alguns testes e instrumentos } \\
\text { psicológicos de orientação escolar e profissional. }\end{array}$ \\
\hline \multicolumn{2}{|r|}{ Teoria e Intervenção em Psicologia da Carreira } \\
\hline $\begin{array}{l}\text { Aconselhamento de } \\
\text { Carreira Online }\end{array}$ & $\begin{array}{l}\text { Abordagem tradicional (face a face) e online do aconselhamento da carreira; } \\
\text { Aspetos práticos e considerações éticas do aconselhamento online (carreira). }\end{array}$ \\
\hline $\begin{array}{l}\text { Modalidades Diretas e } \\
\text { Indiretas de } \\
\text { Intervenção } \\
\text { Psicológica } \\
\text { Vocacional }\end{array}$ & $\begin{array}{l}\text { Elaboração, implementação e avaliação de projetos de intervenção psicológica } \\
\text { vocacional; } \\
\text { Modalidades da consulta psicológica. }\end{array}$ \\
\hline $\begin{array}{l}\text { Modelos de Carreira } \\
\text { e Consulta } \\
\text { Vocacional }\end{array}$ & $\begin{array}{l}\text { Principais modelos conceptuais de compreensão e de intervenção de carreira; } \\
\text { As variáveis de processo e de resultado na consulta vocacional e a sua relação com os } \\
\text { diferentes modelos teóricos: fases, técnicas e procedimentos da consulta. }\end{array}$ \\
\hline $\begin{array}{l}\text { Modelos e } \\
\text { Intervenções em } \\
\text { Psicologia Vocacional }\end{array}$ & $\begin{array}{l}\text { Tarefas de vida e tarefas vocacionais de cada fase de desenvolvimento desde a infância } \\
\text { à 3. - idade; } \\
\text { Perspetivas teóricas da Psicologia Vocacional: conceitos e metodologias de } \\
\text { intervenção; } \\
\text { Intervenções individuais e grupais no âmbito da Psicologia Vocacional: objetivos, } \\
\text { metodologias e destinatários. }\end{array}$ \\
\hline Psicologia Escolar & $\begin{array}{l}\text { Modelos teóricos de tomada de decisão e da intervenção vocacional e da carreira; } \\
\text { Necessidades e competências vocacionais das principais fases do desenvolvimento. }\end{array}$ \\
\hline $\begin{array}{l}\text { Psicologia da } \\
\text { Educação a) }\end{array}$ & $\begin{array}{l}\text { Introdução de conceitos e teorias da psicologia vocacional; } \\
\text { Análise do desenvolvimento vocacional e principais estratégias de intervenção ao } \\
\text { longo da vida. }\end{array}$ \\
\hline $\begin{array}{l}\text { Psicologia da } \\
\text { Educação a) }\end{array}$ & $\begin{array}{l}\text { Principais modelos de intervenção na Psicologia Escolar e da Educação (e.g., } \\
\text { aconselhamento psicológico em meio escolar e orientação vocacional). }\end{array}$ \\
\hline
\end{tabular}




\begin{tabular}{|c|c|}
\hline $\begin{array}{c}\text { Unidades } \\
\text { Curriculares }\end{array}$ & Conteúdos \\
\hline \multicolumn{2}{|r|}{ Fundamentação Conceptual das Problemáticas mais frequente } \\
\hline $\begin{array}{l}\text { Aconselhamento e } \\
\text { Orientação nas } \\
\text { Transições }\end{array}$ & $\begin{array}{l}\text { Modelos de desenvolvimento humano, aconselhamento individual e de grupo aplicados } \\
\text { às transições. }\end{array}$ \\
\hline
\end{tabular}

\section{DISCUSSÃO}

O presente estudo procurou compreender a representatividade da Psicologia Vocacional e do Desenvolvimento de Carreira, por comparação às restantes especialidades definidas pela OPP (Regulamento n. - 107-A/2016), nos cursos de Psicologia em Portugal. Na análise das 1.166 unidades curriculares, entre os 46 cursos selecionados, contata-se que aproximadamente $2.7 \%$ destas abordam temáticas da Psicologia Vocacional e do Desenvolvimento de Carreira. Deste modo, percebe-se que apesar de marcar presença nas restantes especialidades avançadas da psicologia da educação (29.4\%), está claramente pouco representada na formação geral dos/as psicólogos/as. Esta lacuna formativa pode justificar-se pelo facto de esta especialidade avançada ser parte integrante de uma área ainda em desenvolvimento e afirmação em Portugal, a Psicologia da Educação (Mendes et al., 2015). De facto, os resultados encontrados demonstram que a oferta formativa, disponibilizada no ano letivo 2019/20, ainda apresenta um menor enfoque na Psicologia da Educação (7.9\%), em comparação com outras áreas como a Psicologia Clínica e da Saúde (27.4\%). Porém, é importante enquadrar estes resultados no acesso limitado à totalidade dos conteúdos programáticos dos cursos de psicologia, em formato online. Assim, sugere-se que, em futuros estudos se procure reunir informação mais completa acerca dos planos curriculares nos diversos ciclos de estudo recolhendo-os diretamente junto das instituições de ensino superior públicas e privadas.

Na análise aos conteúdos das 31 unidades curriculares no âmbito da Psicologia Vocacional e do Desenvolvimento de Carreira destacam-se duas conclusões. Em primeiro lugar, observa-se um maior enfoque na categoria "Concetualização teórica, avaliação e intervenção em problemáticas da psicologia da carreira". Tal parece indicar a preferência por uma abordagem generalista, na qual se procura fazer a interface entre a teoria, avaliação e intervenção nesta área. Por um lado, este tipo de abordagem pode ser positivo no sentido de fornecer uma melhor contextualização para as diferentes componentes da prática. No entanto, poderá ser redutor na preparação dos profissionais na intervenção em problemáticas mais específicas. Futuros estudos, com recurso a uma descrição detalhada dos conteúdos programáticos lecionados, nomeadamente com conhecimento acerca dos modelos concetuais e metodológicos abordados, poderão explorar quais os referenciais mais úteis para as problemáticas de carreira emergentes na atualidade. Assim, será possível facultar às instituições de ensino superior e outras entidades formativas referenciais que lhes permitam organizar a formação de uma forma que seja relevante para a capacitação dos futuros psicólogos. Em segundo lugar, é importante destacar a subrepresentatividade de conteúdos programáticos focados nas seguintes competências-chave: gerir e implementar programas de carreira em diferentes contextos e populações; conhecimentos e competências sobre coaching, consultoria e otimização de desempenho; conhecimentos e competências de supervisão; e conhecimentos e competências de prática investigativa (IAEVG, 2018; NCDA, 2009). Estas limitações talvez possam ser compreendidas pelo número reduzido de unidades curriculares com cariz prático, assim como pelo facto de estes conhecimentos e competências serem lecionados em unidades curriculares comuns às restantes especialidades da Psicologia. A par desta questão, não é possível garantir que a totalidade das competências-chave requeridas para o exercício da profissão sejam adquiridas em cada curso de Psicologia, sobretudo tratando-se da formação inicial. Reforça-se assim, a importância da comunicação entre as próprias instituições de formação bem como, entre estas e as entidades laborais no sentido da reavaliação da oferta formativa com base no levantamento das dificuldades e necessidades sentidas por estes/as profissionais em situação real de desempenho profissional. Sugere-se assim, que este levantamento possa vir a constituir-se como o objetivo de partida para um estudo a realizar em parceria pelas faculdades/escolas de Psicologia e pelos empregadores no qual a Ordem dos Psicólogos Portugueses poderá vir a tomar parte.

As eventuais discrepâncias entre as exigências profissionais e a oferta formativa podem, em parte, dever-se ao processo moroso da reforma pós-Bolonha (Macedo, 2017). Esta reforma continua a refletir-se nos cursos de Psicologia pelas oscilações no número de licenciaturas, mestrados, mestrados integrados e doutoramento. Nomeadamente, de 2015/16 (Cordeiro et al., 2018) para 2019/20 houve um aumento do número de mestrados de 47 para 55 e dos doutoramentos de 11 para 23. Tal pode justificar-se pela exigência crescente de pessoas mais qualificadas no exercício da profissão, isto é, capazes de responder às exigências do mercado de emprego (e.g., Comissão Europeia, 2019; Fórum Económico Mundial, 2018). Porém, os resultados da DGEEC (2018) continuam a indicar que a Psicologia é a segunda área com um 
maior número de diplomados desempregados. Estes resultados parecem reforçar a necessidade de maximizar o potencial da formação, tendo por base um perfil de competências dos/as os/as psicólogos/as (Mendes et al., 2015) e as exigências do mercado de trabalho (Macedo, 2017). Sob um outro ponto de vista, importa ter em conta que a inclusão de unidades curriculares no âmbito da Psicologia Vocacional e do Desenvolvimento de Carreira nos diferentes ciclos de ensino da psicologia, independentemente da área de especialização, poderá, inclusive, facilitar a promoção de competências-chave essenciais para a gestão pessoal de carreira dos/as próprios/as psicólogos/as que, assim, poderão ficar mais equipados/as para responder melhor face a situações de desemprego e outros desafios da sua carreira.

\section{REFERÊNCIAS}

Blustein, B. L., Ali, S.R., \& Flores, L.Y. (2019). Vocational psychology: Expanding the vision and enhancing the impact. The Counseling Psychologist, 47(2), 221. https://doi.org/10.1177/0011000019861213

Cedefop (2019). Investing in career guidance. https://www.cedefop.europa.eu/en/publications-andresources/publications/2227

Coelho, V., Brás, P., Pereira, L., \& Amaro, A. (2012). Um país de psicólogos? Análise da formação universitária em psicologia em Portugal. In C. Silva (Ed.), Um país de psicólogos? (pp. 14-15). Ordem dos Psicólogos Portugueses.

Comissão Europeia (2018). The European higher education areas in 2018: Bologna process implementation report. Publication Office of European Union. https://eacea.ec.europa.eu/nationalpolicies/eurydice/sites/eurydice/files/bologna_internet_0.pdf

Comissão Europeia (2019). The Changing Nature of Work and Skills in the Digital Age. https://ec.europa.eu/jrc/en/publication/eur-scientific-and-technical-research-reports/changingnature-work-and-skills-digital-age

Cordeiro, S., Rodrigues, B., Taveira, M. C., Marques, C., Oliveira, Í., Silva, A. D., \& Costa-Lobo, C. (2018). Ensino da psicologia e da psicologia da carreira: 0 presente e implicações futuras. PSIQUE, 14, 40-55. https://doi.org/10.26619/2183-4806.14.3

Decreto-Lei no 107/2008 de 25 de Junho do Ministério da Ciência, Tecnologia e Ensino Superior. Diário da República, 1. - Série, 121 (2008).

Direção-Geral de Estatísticas de Educação e Ciência do Ministério da Educação e Ciência (2015). Caracterização dos desempregados registados com habilitação superior - dezembro 2015. http://www.dgeec.mec.pt/np4/92/

Direção-Geral de Estatísticas de Educação e Ciência do Ministério da Educação e Ciência (2016). Caracterização dos desempregados registados com habilitação superior - dezembro 2016. http://www.dgeec.mec.pt/np4/92/

Direção-Geral de Estatísticas de Educação e Ciência do Ministério da Educação e Ciência (2017). Caracterização dos desempregados registados com habilitação superior - dezembro 2017. http://www.dgeec.mec.pt/np4/92/

Direção-Geral de Estatísticas de Educação e Ciência do Ministério da Educação e Ciência (2018). Caracterização dos desempregados registados com habilitação superior - dezembro 2018. http://www.dgeec.mec.pt/np4/92/

Direção-Geral do Ensino Superior (2019). Índice por curso e Instituição. https://www.dges.gov.pt/guias/indcurso.asp

Duarte, M. E., Lassance, M. C., Savickas, M. L., Nota, L., Rossier, J., Dauwalder, J. P., Guichard, J., Soresi, S., Esbroeck, R., \& van Vianen, A. E. (2010). A construção da vida: Um novo paradigma para entender a carreira no século XXI. Interamerican Journal of Psychology, 44(2), 392-406.

Fórum Económico mundial (2018). The future of Jobs Report 2018. http://www3.weforum.org/docs/WEF_Future_of_Jobs_2018.pdf

Gama, A., Vale, C., Silva, A.D., \& Carvalho, M. (2018). Papel da psicologia da carreira para o cumprimento da agenda 2030. In M. C. Taveira, A. D. Silva, C. Marques \& M. Leal (Ed.), Desenvolvimento de Carreira e Aconselhamento: Educação, Mobilidade e Emprego (pp. 139-150). Associação Portuguesa para o desenvolvimento de Carreira

IAEVG (2018). International competencies for educational and vocational guidance practitioners. https://iaevg.com/Framework

Lent, R. W. (2018). Future of Work in the Digital World: Preparing for Instability and Opportunity. The Career Development Quarterly, 66, 205-219. https://doi.org/10.1002/cdq.12143

Macedo, B. (2017). O Processo de Bolonha: Discursos e dinâmicas da reformulação educacional nas universidades da União Europeia. Algumas reflexões. Debater a Europa, 16, 209-219. https://doi.org/10.14195/1647-6336_16_9 
Mendes, A.S., Abreu-Lima, I., \& Almeida, L.S. (2015) Psicólogos escolares em Portugal: perfil e necessidades de formação, Estudos de Psicologia, 32(3), 405-416. https://doi.org/10.1590/0103166X2015000300006

NCDA (2009).

Career Counseling

Competencies. https://www.ncda.org/aws/NCDA/pt/sd/news_article/37798/_self/layout_ccmsearch/true

Ordem dos Psicólogos Portuguese (2013). Ordem dos Psicólogos cria Bolsa de Emprego. https://www.ordemdospsicologos.pt/pt/noticia/1072

Ordem dos Psicólogos Portuguese (2016). Ordem dos Psicólogos Portugueses propõe contratação de mais 447 Psicólogos no SNS. https://www.ordemdospsicologos.pt/pt/noticia/1739

Ordem dos Psicólogos Portuguese (2018). Proposta para o Orçamento de Estado de 2019. http://recursos.ordemdospsicologos.pt/files/artigos/opp_oe19_1_.pdf

Regulamento no 107-A/2016 de 29 de Janeiro do Ministério da Ciência, tecnologia e Ensino Superior. Diário

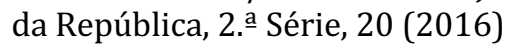

Savickas, M. L. (2012). Life Design: A Paradigm for Career Intervention in the 21st Century. Journal of Counseling \& Development, 90(1), 13-19. https://doi.org/10.1111/j.1556-6676.2012.00002.x

Whiston, S. C. \& Blustein, D. L. (2013). The Impact of Career Interventions: Preparing our Citizens for 21st Century Jobs. National Career Development Association and the Society for Vocational Psychology

$\begin{array}{lr}\text { Historial do artigo } \\ \text { Recebido } & 05 / 2020 \\ \text { Aceite } & 10 / 2020 \\ \text { Publicado } & 12 / 2020\end{array}$

